Coatings 2011, 1, 117-132; doi:10.3390/coatings1020117

Review

\title{
Very Low Pressure Plasma Spray-A Review of an Emerging Technology in the Thermal Spray Community
}

\author{
Mark F. Smith ${ }^{1}{ }^{*}$, Aaron C. Hall ${ }^{1}$, James D. Fleetwood ${ }^{2}$ and Philip Meyer $^{3}$ \\ 1 Sandia National Laboratories, 1515 Eubank SE, Albuquerque, NM 87123, USA; \\ E-Mail: achall@sandia.gov
}

2 School of Materials Engineering, Purdue University, 701 West Stadium Avenue, West Lafayette, IN 47907, USA; E-Mail: jdf@purdue.edu

3 Sulzer-Metco, 1101 Prospect Avenue, Westbury, NY 11590-2724, USA;

E-Mail: Phil.Meyer@sulzer.com

* Author to whom correspondence should be addressed; E-Mail: mfsmith@sandia.gov;

Tel.: +1-505-845-3256; Fax: +1-505-284-3093.

Received: 30 October 2011; in revised form: 11 December 2011 / Accepted: 17 December 2011 /

Published: 20 December 2011

\begin{abstract}
A fundamentally new family of thermal spray processes has emerged. These new processes, collectively known as very low pressure plasma spray or VLPPS, differ from traditional thermal spray processes in that coatings are deposited at unusually low chamber pressures, typically less than $\sim 800 \mathrm{~Pa}$ (6 Torr). Depending upon the specific process, deposition may be in the form of very fine molten droplets, vapor phase deposition, or a mixture of vapor and droplet deposition. Resulting coatings are similar in quality to coatings produced by alternative coating technologies, such as physical vapor deposition (PVD) or chemical vapor deposition (CVD), but deposition rates can be roughly an order of magnitude higher with VLPPS. With these new process technologies modified low pressure plasma spray (LPPS) systems can now be used to produce dense, high quality coatings in the 1 to 100 micron thickness range with lamellar or columnar microstructures. A history of pioneering work in VLPPS technology is presented, deposition mechanisms are discussed, potential new applications are reviewed, and challenges for the future are outlined.
\end{abstract}


Keywords: Very Low Pressure Plasma Spray (VLPPS); Plasma Spray-Thin Film (PS-TF); Vacuum Plasma Spray (VPS); Plasma Spray-Physical Vapor Deposition (PS-PVD); Plasma Spray-Chemical Vapor Deposition (PS-CVD); Low Pressure Plasma Spray Thin Film (LPPS-TF®); Low Pressure Plasma Spray (LPPS)

\section{Introduction}

The plasma spray process, invented circa 1940, remains one of the most versatile and widely used thermal spray processes. Over the years, process improvements have enhanced the quality and consistency of materials deposited with plasma spray, in conjunction with a continually expanding range of applications for plasma spray coatings. For example, wide-spread adoption of controlled atmosphere spraying in the 1980's (commonly referred to as Low Pressure Plasma Spray-LPPS ${ }^{\text {TM }}$ or Vacuum Plasma Spray - VPS ${ }^{\mathrm{TM}}$ ) greatly enhanced the quality of plasma sprayed metal coatings. This led to many new applications, such as coating critical turbine engine parts and medical implants. Advancements in process understanding and controls as well as improvements in plasma torch design have also contributed to improved coating quality and greater product uniformity. However, despite significant improvements over several decades, the basic process technology, i.e., heating of powder particles to spray-deposit molten or semi-molten droplets onto line-of sight substrate surfaces, has remained essentially the same.

This review discusses some intriguing developments in plasma spray technology that offer the opportunity move beyond some of the traditional limitations of plasma spray technology and prepare coatings using fundamentally different deposition mechanisms. This new technology offers the capability to very rapidly deposit a wide range of materials, not just as molten droplets, but also from the vapor phase, using solid, liquid, and even gaseous feedstock. It also offers increased plasma velocity compared to traditional vacuum plasma spray. The resulting coatings are similar in many respects to coatings traditionally produced by physical vapor deposition (PVD) or chemical vapor deposition (CVD) processes. However, deposition rates are approximately an order of magnitude higher than traditional PVD and CVD processes, e.g., $\sim 5 \mu \mathrm{m} /$ minute compared to $\sim 0.5 \mu \mathrm{m} /$ minute. These new process technologies can produce dense (90\% theoretical density) coatings with thicknesses on the order of 1 to 100 microns. Finally, unlike traditional plasma spray, this emerging process technology is not strictly limited to line-of-sight deposition.

This review begins with a brief discussion of a Low Pressure Plasma Spray system at Sandia National Laboratories, Albuquerque, NM, that was modified to achieve continuous operation at chamber pressures down to $\sim 133 \mathrm{~Pa}$ (1 Torr). The properties of a plasma jet at very low pressures are then reviewed, followed by a discussion of various different process operating regimes and some resulting coating properties based on the limited data currently available. Finally, some brief comments are provided about potential applications of this new technology. 


\section{Origins of Very Low Pressure Plasma Spraying}

In the mid 1990's the late Eric Muehlberger, a creative pioneer in LPPS technology, began working with Sulzer Metco to explore new ways to rapidly and inexpensively apply very thin, highly uniform dielectric coatings over large surface areas (many square meters) of metal sheet. This led to a 1998 US Patent \#5853815 entitled "Method of Forming Uniform Thin Coatings on Large Substrates", which describes the use of a modified LPPS system operated at high power and with chamber pressures well below the customary operating envelope. Since that time, others at Sulzer Metco and elsewhere have refined and extended the concept of operating at very low chamber pressures. Multiple new alternatives have been developed for using modified LPPS systems to rapidly deposit thin sprayed coatings from fine molten droplets or vapor deposited coatings from solid, liquid, or gas feedstock. The terminology for these new process technologies is not entirely consistent among various authors. In this paper, we adopt the following terminology: Plasma Spray-Thin Film (PS-TF) refers to a process with powder feedstock where deposition is predominantly by molten droplets, similar to conventional plasma spray, but at greatly reduced chamber pressures; Plasma Spray-Physical Vapor Deposition (PS-PVD) refers to a process in which powder feedstock is vaporized and deposition occurs primarily from the vapor phase; Plasma Spray - Chemical Vapor Deposition (PS-CVD) refers to a process that utilizes liquid or gas feedstock with deposition from the vapor phase; and Very Low Pressure Plasma Spray (VLPPS) will refer to the entire family of reduced pressure $(<800 \mathrm{~Pa}(<6$ Torr)) plasma spray technologies as just described.

\section{Operating an LPPS System at Pressures Below $1.3 \mathrm{kPa}$ (10 Torr)}

The Low Pressure Plasma Spray System at Sandia National Laboratories (Figure 1) consists of a large $(\sim 3500 \mathrm{~L} ; \sim 2 \mathrm{~m}$ tall $\times \sim 1.5 \mathrm{~m}$ dia. $)$ water-cooled vacuum chamber manufactured by the former Electro-Plasma, Inc. of Irvine, California. A Sulzer Metco 03C plasma torch connected to a custom-built 2000A, 50V (open circuit) Halmar power supply is used for all spraying. Under normal operation, the plasma torch steadily introduces over 100 SLPM of process gas into the vacuum chamber. In order to maintain the chamber at the very low dynamic pressures needed for VLPPS operation, the original LPPS pumping system was augmented with a second, parallel, vacuum pumping system. Each vacuum pumping system consists of a roughing pump and a blower. One system is a Stokes model 615-1 blower backed by a Stokes 412-11 roughing pump. The other system is a Kinney KMBD1600-90L2 blower backed by a Kinney KT300 roughing pump. When operated simultaneously, these systems offer a total pumping capacity of $\sim 82,000$ SLPM (2900 CFM). This system allows steady-state operation at chamber pressures down to $\sim 133 \mathrm{~Pa}$ (1 Torr). A custom-built five axis robotic system is integrated into the vacuum chamber and is used to manipulate the spray torch and/or the substrate. Feedstock delivery is accomplished using either a Brigs model 171D dry powder hopper or a custom built liquid suspension delivery system. All system control is accomplished through custom LabView ${ }^{\mathrm{TM}}$ software, which monitors and controls process inputs including: plasma gas flows and pressures, plasma current and voltage, chamber pressure, and plasma enthalpy (calculated from cooling water temperature rise). In addition, the vacuum chamber can be outfitted with an MKS residual gas analyzer, a FLIR infrared camera, and various thermocouples. 
Figure 1. Sandia's very low pressure plasma spray system.

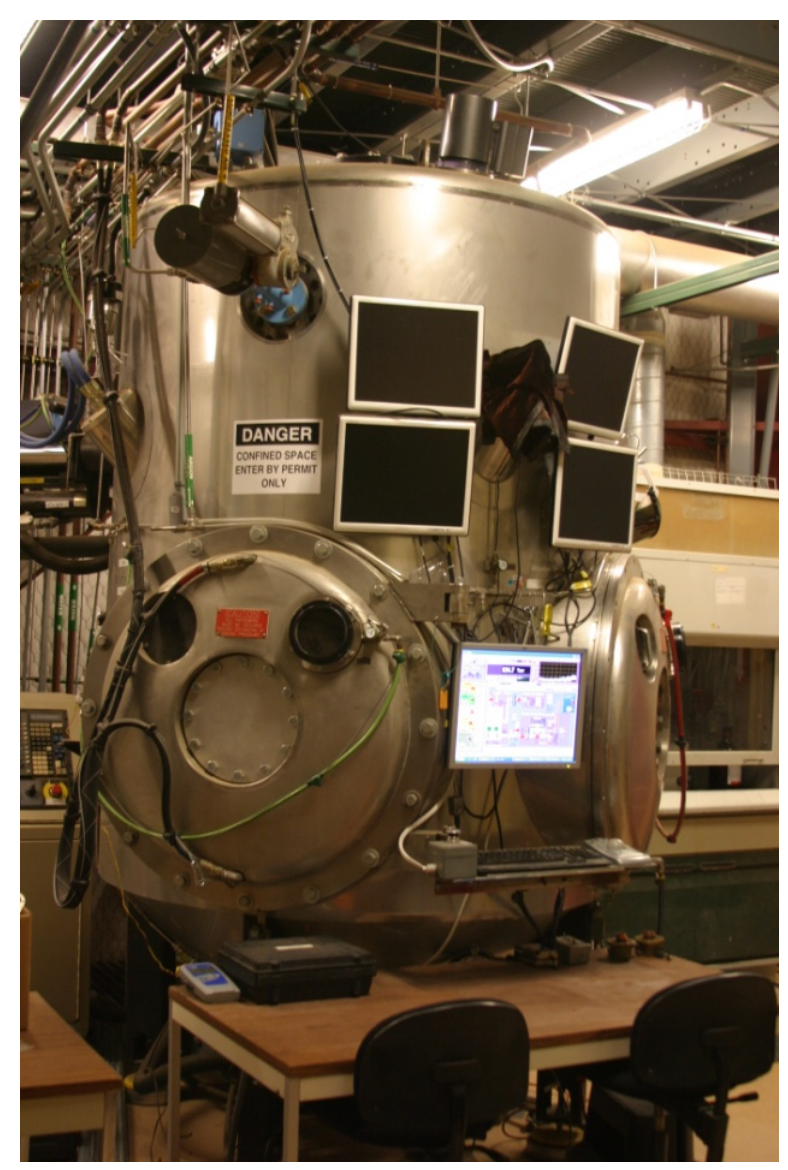

Torch stability and electrode wear are always a concern when operating a plasma torch at unusual conditions. In initial VLPPS operations at Sandia, very rapid degradation of the anode was experienced. Without modification, a standard BPC-353-113 anode deteriorated by melting and erosion of the arc chamber in times on the order of tens of minutes. It was necessary to modify the internal anode geometry in order to achieve an acceptable lifetime. The modified anode is shown in Figure 2. This modified anode geometry is based on the 03CA-97 anode with the diameter of the arc chamber increased to reduce the energy density in the arc chamber and improve water cooling efficiency. This modification resulted in significantly less arc chamber erosion and less local melting of the anode surface. The throat of this anode is designed for free expansion of the plasma at reduced pressures. A standard $12.7 \mathrm{~mm}(0.50 \mathrm{inch})$ diameter tungsten cathode (BPC-155-112) is used without modification. 
Figure 2. Custom anode used with the 03C torch for VLPPS spraying at Sandia. This anode is based on the 03CA-97 anode, the arch chamber and throat dimensions have been modified to minimize anode wear.

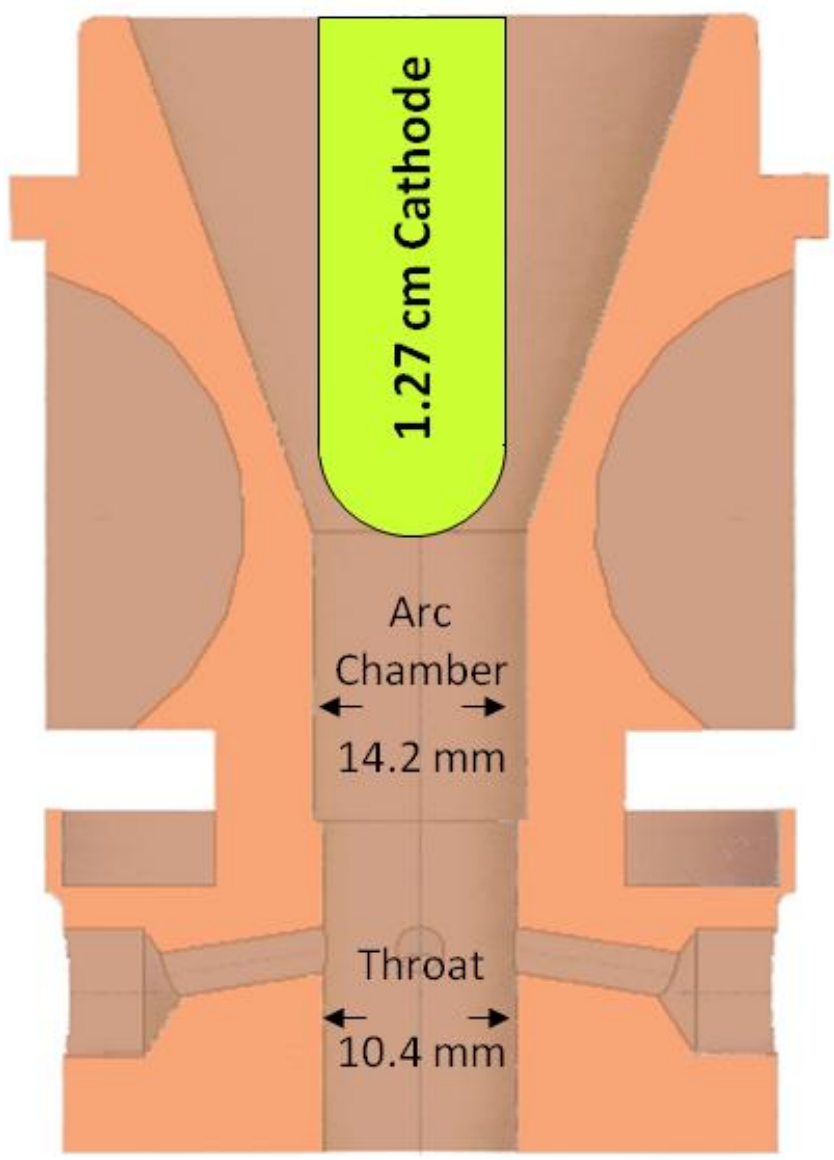

A plot of voltage versus time for the modified anode is shown in Figure 3. Stable operation $(+/-2$ volts) was achieved for 8 hours, even with multiple high frequency starts.

Recently, improved anodes $(264,270,271)$ and an accompanying water cooling jacket have become available for the 03CA torch. These anodes are tungsten lined increasing the durability of the arc chamber and nozzle. In addition, they are configured so that water cooling near the front of the anode and around the powder injection ports is improved. Each of these anodes has a large arc chamber and a short nozzle. Experience at SNL has shown these anodes can be operated for well over 8 hours at VLPPS conditions. 
Figure 3. Voltage trace from an 8 hour run using a single anode. Voltage spikes are associated with high frequency arc starts.

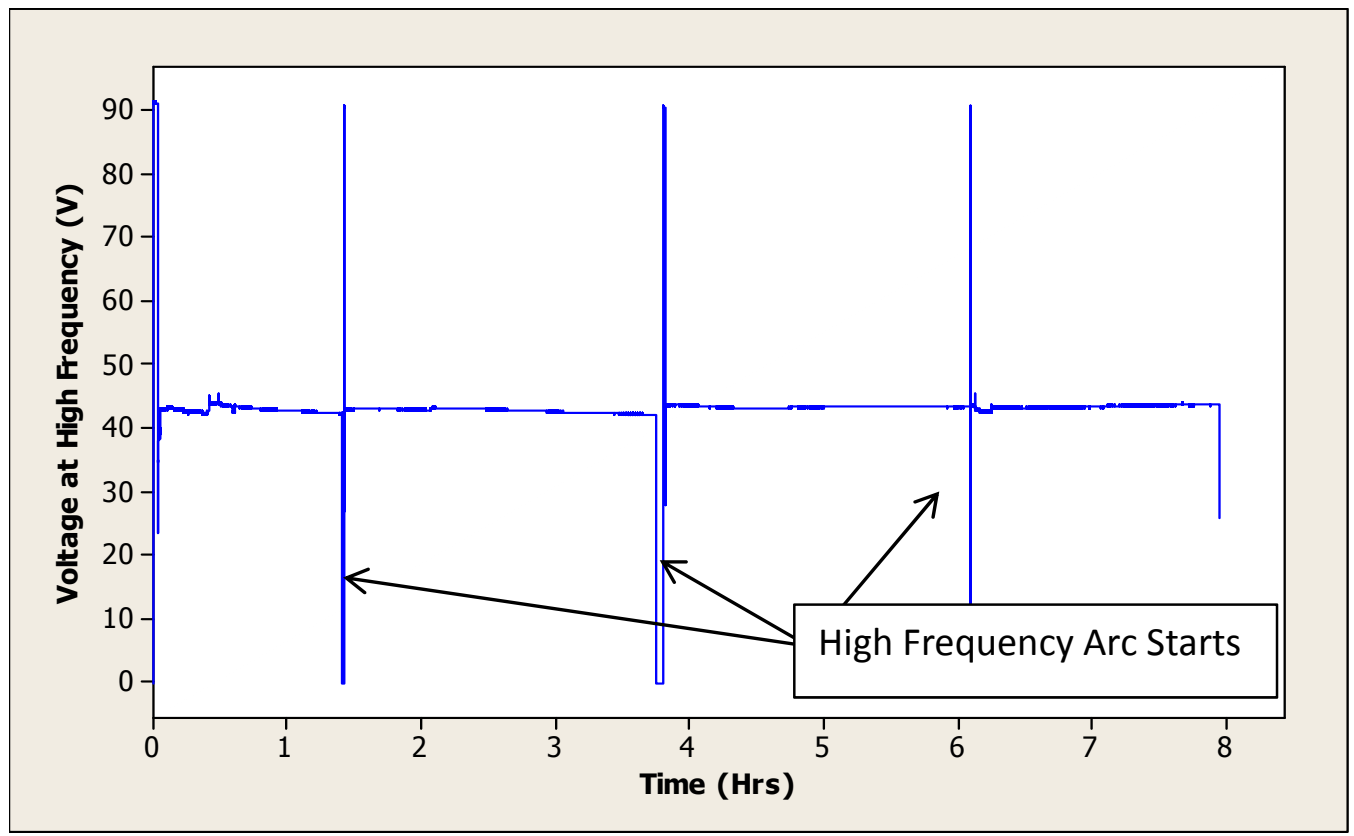

\section{Plasma Jet Properties at Very Low Chamber Pressures}

Traditionally, LPPS systems are operated at chamber pressures on the order of 5 to $20 \mathrm{kPa}$ (37 to 150 Torr). In contrast, VLPPS systems typically operate at chamber pressures on the order of 100 to $500 \mathrm{~Pa}(0.75$ to 3.75 Torr). At these greatly reduced pressures, the plasma jet expands and lengthens significantly. Figure 4 compares plasma jets in the Sandia VLPPS system at pressures ranging from $760 \mathrm{~Pa}$ (5.7 Torr) down to $387 \mathrm{~Pa}$ (2.9 Torr). Even over this relatively modest pressure change, dramatic changes in the plasma jet are observed. The jet at the lowest pressure is more than $20 \mathrm{~cm}(\sim 10 \mathrm{in})$ in diameter and extends to the base of the chamber, more than $1 \mathrm{~m}(3.3 \mathrm{ft})$ from the spray torch.

An experimental study of jet properties under the conditions of interest was conducted by Dorier et al. [2]. Their study involved a Sulzer Metco 03CP spray gun operating at $1500 \mathrm{~A}$ and $43 \mathrm{~V}$ with an $\mathrm{H}_{2} / \mathrm{Ar}$ arc forming gas at flow rates of 3/100 SLPM. The pressure range investigated was $1 \mathrm{kPa}$ to $200 \mathrm{~Pa}$ (7.5 to 1.5 Torr). These authors used a specially modified enthalpy probe and optical emission spectroscopy to investigate properties of the plasma jet under these very low pressure conditions. Dorier et al. measured the decrease in plasma jet density as the chamber pressure was decreased. For example, representative values estimated from their data plots at an axial distance of $800 \mathrm{~mm}$ from the nozzle exit indicate approximate jet densities of $6.5 \times 10^{-4} \mathrm{~kg} / \mathrm{m}^{3}, 2.5 \times 10^{-4} \mathrm{~kg} / \mathrm{m}^{3}$, and $0.75 \times 10^{-4} \mathrm{~kg} / \mathrm{m}^{3}$ at 1000,600 , and $200 \mathrm{~Pa}(7.5,4.5$, and 1.5 Torr) chamber pressure respectively. These authors also reported increases in both jet velocity and jet temperature with decreasing chamber pressure. At the same $800 \mathrm{~mm}$ axial distance, their results indicate approximate jet velocities of 1000,2500 , and $3200 \mathrm{~m} / \mathrm{s}$ with corresponding temperatures of $7500,11,000$, and $12,500 \mathrm{~K}$ at 1000,600 , and $200 \mathrm{~Pa}$ respectively. These 
authors also conducted radial studies of jet properties and concluded that for very low pressures, on the order of $200 \mathrm{~Pa}$, the temperature and velocity of the highly expanded jet are essentially constant up to $20 \mathrm{~mm}$ from the jet centerline. They attributed this to the low density of the surrounding chamber gas and laminar jet flow (Reynolds number $\sim 100$ ) resulting in weak interactions between the jet and the surrounding chamber atmosphere. They also noted that the collision rate at these chamber pressures is strongly reduced and, therefore, the assumption of local thermodynamic equilibrium may no longer be valid. Although the behavior of high energy density plasma at the pressures associated with VLPPS is not well understood, it has been reported that heat transfer is no longer collision dominated in these lower pressure regimes [2, 29-33].

Figure 4. Dramatic expansion of the plasma jet as pressure is reduced.

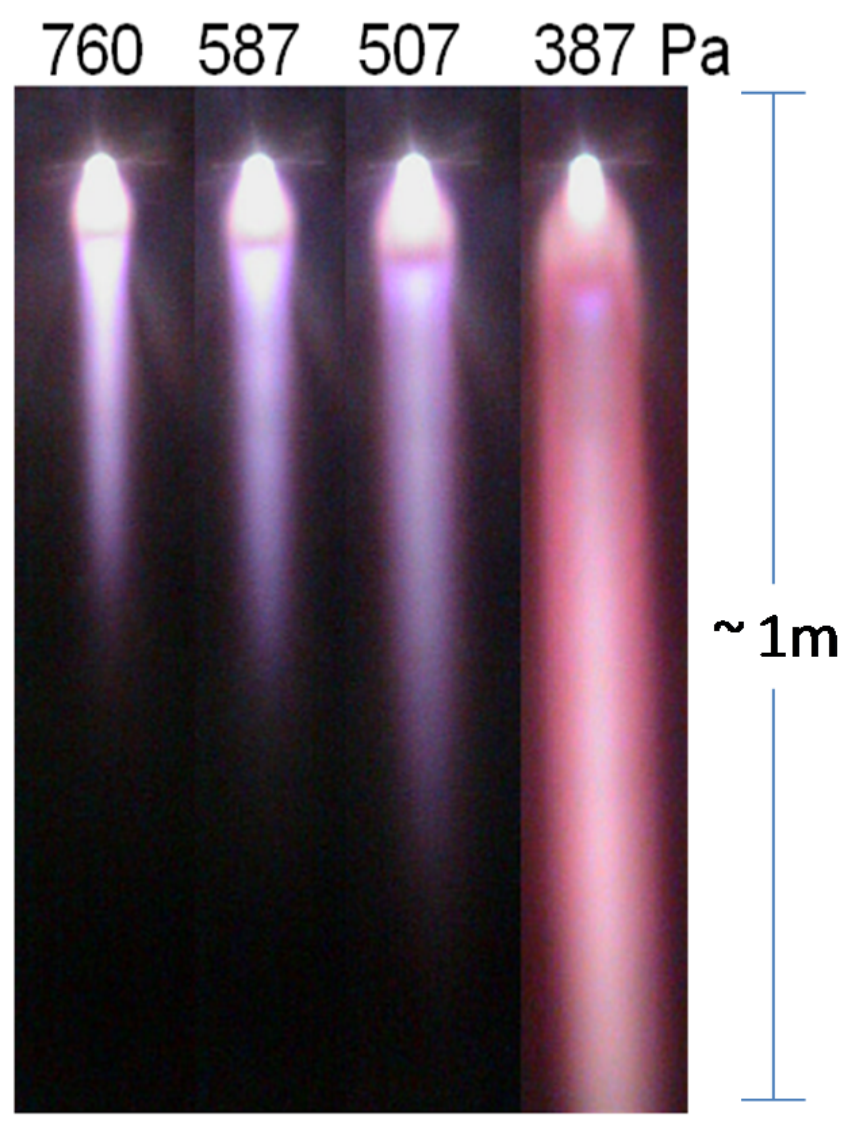

Complex interactions exist between the feedstock material and the VLPPS plasma, most of which can currently only be inferred based on plasma spray research at higher pressures [34-37]. If very fine powder ( $<15$ microns) is injected into the plasma jet at very low pressures, the small particles tend to follow expansion of the jet and distribute across the plume. Considerable vaporization of the powder also occurs at high power levels. This is evident in Figure 5, where 5 micron copper powder injected into a VLPPS plasma jet produces an intense green emission from multiple spectral lines of copper vapor in the 505-530 nm wavelength range [1]. 
Figure 5. (a) VLPPS plasma jet expanding into a vacuum chamber held at $\sim 133 \mathrm{~Pa}$. (b) Injecting 5 micron $\mathrm{Cu}$ powder into the plasma jet produces intense green emission from copper vapor.

(a)

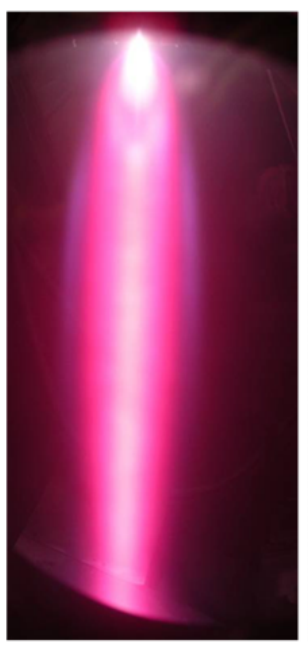

(b)

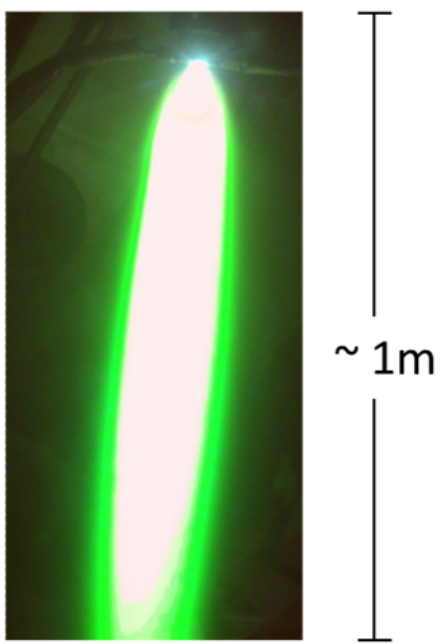

Phase transformation pathways and how process inputs affect feedstock treatment are also not well understood, though visible emission upon feedstock injection clearly indicates that the vaporized feedstock can be excited in the plasma prior to deposition. As Figure 6 illustrates, there are multiple potential pathways for phase transition of feedstock materials in a VLPPS process. These processes may be further complicated with chemical precursor feedstocks that react or pyrolize within the plasma $[5,8,27]$.

Figure 6. A generic phase diagram showing potential phase transformation pathways from initial feedstock entrainment into the plasma to deposition on a substrate.

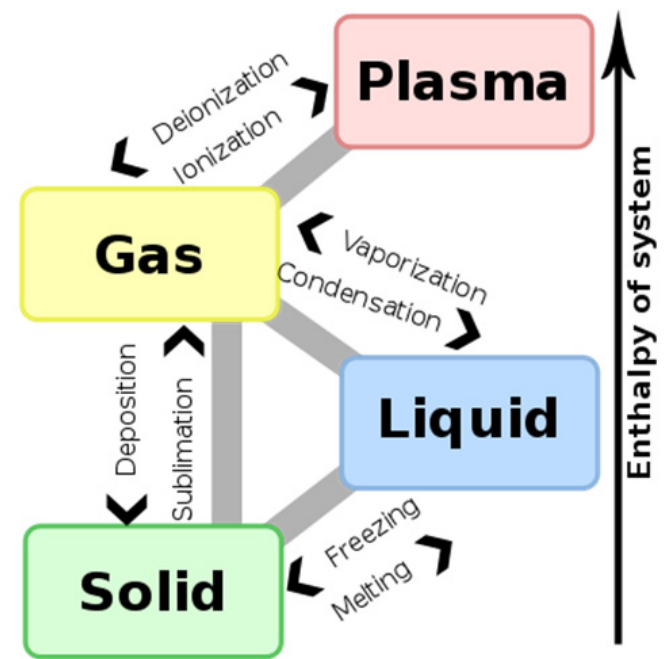




\section{Coating Examples (PS-PVD and PS-TF)}

Sulzer-Metco has published a number of papers on the PS-TF process invented by Eric Muehlberger, originally referred to as Low Pressure Plasma Spray-Thin Film (LPPS-TF®) [3,4-8]. These papers clearly show that Yttria-Stabilized Zirconia (YSZ) coatings with highly columnar microstructures can be prepared using the LPPS-TF® process. This work also shows that process parameters significantly affect the density and morphology of the columnar microstructure. In addition, they show that both droplet and vapor deposition mechanisms can be used to prepare thin dense coatings. In the case of droplet deposition, thin dense coatings with a typical lamellar microstructure were demonstrated.

Sandia National Laboratories, in collaboration with The New Mexico Institute of Mining and Technology, has also published work on the preparation of YSZ using VLPPS [9]. The purpose of this work was to better understand the VLPPS YSZ coatings for application as solid-oxide fuel cell electrolytes. In the course of that work, the LPPS-TF® results reported by Refke et al. were confirmed [9]. Specifically, Sandia was able to confirm that the VLPPS process is capable of preparing thin dense coatings with lamellar microstructures indicative of liquid droplet deposition (Figure 7), as well as columnar microstructures (Figure 8) similar to those observed in vapor deposition processes, such as PVD or CVD. Notably, the 40 micron thick YSZ film shown in Figure 8, was prepared in less than 10 minutes of actual spray time. In addition, Sandia showed that VLPPS can be used to prepare coatings with microstructures that include both lamellar and columnar features, suggesting a mixed-mode deposition (Figure 9).

Figure 7. PS-TF A12O3 coating prepared at Sandia using droplet deposition. A lamellar structure characteristic of liquid droplet deposition can be clearly seen.

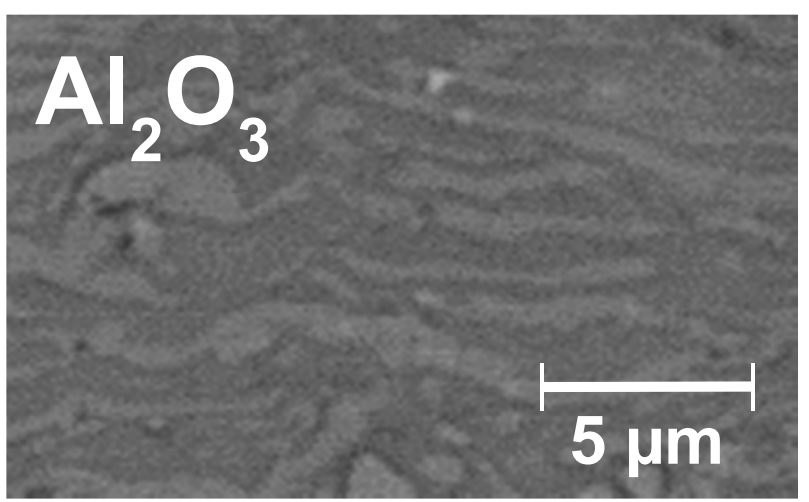


Figure 8. PS-PVD YSZ coating prepared at Sandia. The coating is over 40 microns thick. Columnar structures similar to vapor deposited coatings can be clearly seen. For example Figure 1, Reference [10], shows similar columnar structure in a Electron Beam PVD YSZ coating.

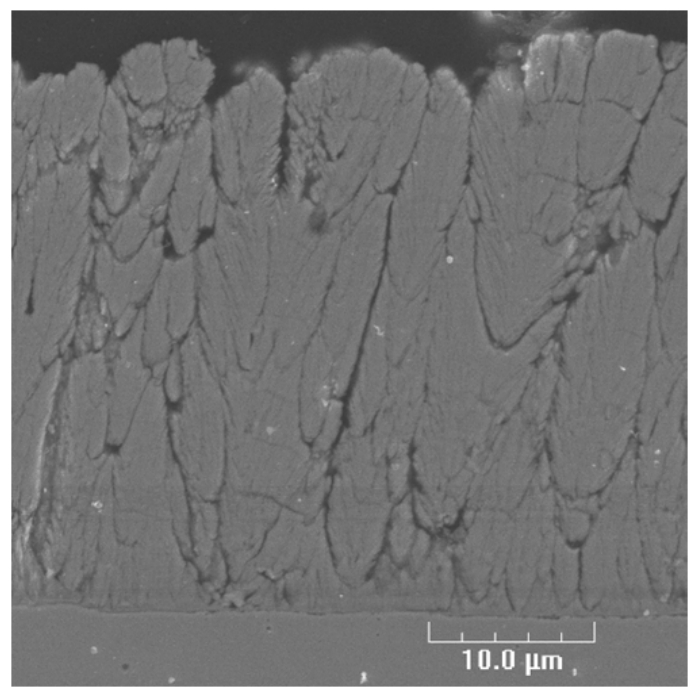

Figure 9. VLPPS mixed-mode YSZ coating prepared at Sandia. The coating is over 100 microns thick. Lamellar structures characteristic of liquid droplet deposition and columnar structures (arrow) suggestive of vapor deposition can be clearly seen.

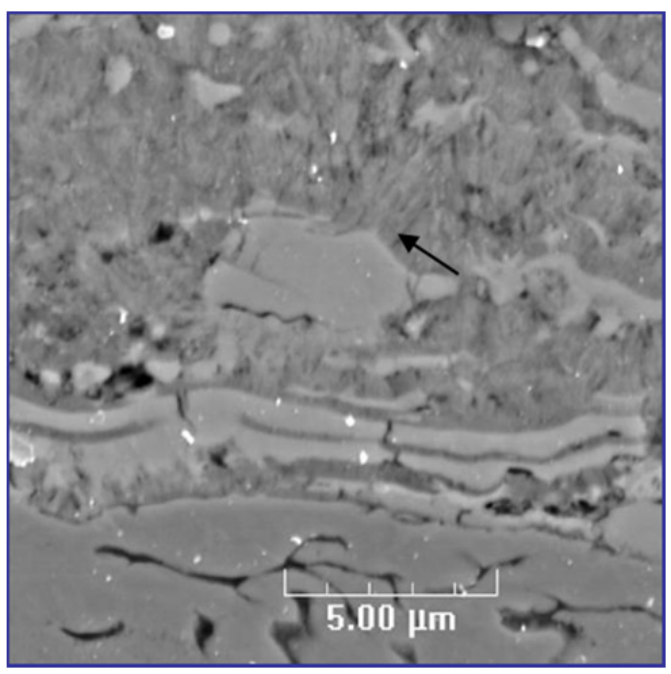

Mixed mode YSZ coatings were reported by Hospach et al. [11]. Vapor deposited copper coatings were reported by Zhang et al. [12]. Thin $(<50 \mu \mathrm{m})$ dense Mg-spinel $\left(\mathrm{MgAl}_{2} \mathrm{O}_{4}\right)$ coatings deposited from droplets were reported by Mauer et al. [13]. Similarly Zhu et al. report thin dense lamellar YSZ coatings [14]. Many other authors have reported examples of PS-PVD coatings [1,6,7,9-13,15-17]. 


\section{Other Feedstock Delivery Approaches}

Feedstock delivery for VLPPS processes is not limited to dry powder. Successful operation has been demonstrated with liquid suspension, liquid precursors, and gaseous feedstocks. Sandia National Laboratories in collaboration with Purdue University has successfully deposited VLPPS coatings with a suspension feedstock delivery of Yttria Stabilized Zirconia particles suspended in ethanol [19]. Coating preparation from liquid precursors that chemically react in the plasma to form a coating have also been demonstrated. Specifically, silicon oxide films prepared from Hexamethyldisiloxane (HMDSO or $\mathrm{C}_{6} \mathrm{H}_{18} \mathrm{OSi}_{2}$ ) are reported by Gindrat et al. and Dorier et al. [5,8]. In addition, both Gindrat and Dorier report the use of gaseous feedstocks. Gasses such as $\mathrm{CH}_{4}$ and $\mathrm{C}_{2} \mathrm{H}_{4}$ were used to prepare amorphous carbon films [8]. Oxide coatings $\left(\mathrm{Al}_{2} \mathrm{O}_{3}, \mathrm{ZnO}\right.$, and $\left.\mathrm{SnO}_{2}\right)$ were prepared by reacting evaporated metals with oxygen [5]. VLPPS using reactive liquid or gaseous feedstocks is termed PS-CVD.

\section{New Applications and Opportunities for VLPPS}

There are many promising applications of VLPPS processes. Primary among them are thermal barrier coatings and solid oxide fuel cells (SOFC). PS-PVD YSZ coatings have microstructures very similar to EB-PVD (electron beam physical vapor deposition), which have a long history of success as thermal barrier coatings. However, the PS-PVD process has the advantages of faster deposition rates, larger spray patterns, and non line-of-sight deposition [1,6,7,9,11,13,15-18].

Plasma spray technologies are already in use for solid oxide fuel cell (SOFC) preparation, but VLPPS has the potential for dramatic improvement over traditional plasma spray [9,15,19-25]. Firstly, the VLPPS system provides dynamic control over the ambient chamber pressure during processing. Thus, entire fuel cell systems can be constructed with measured or graded porosities to optimize each component in the cell [20-23,25]. In addition, the VLPPS process's ability to create thin and dense coatings makes it better suited than traditional thermal spray processes towards meeting the design criteria for SOFC electrolytes $[9,15,19,20,22]$. Furthermore, the columnar structure offers the potential for shorter ion diffusion paths through the electrolyte compared to a lamellar structure. If this could be realized, it would represent an improvement in electrolyte performance.

There are many other untried applications for VLPPS coatings. Among these applications are photocatalytic coatings, wear-resistant coatings, and coatings for biomedical applications [26,27]. To date, the vast majority of work has focused on ceramic coatings, particularly YSZ. Isolated instances of metal coatings have been reported [12]. Figure 10 shows a nickel coating prepared using the PS-TF process at Sandia. The exploration of VLPPS metal coatings could lead to a multitude of other applications, such as replacements for electroplated coatings and wear resistant metal-ceramic composite coatings. 
Figure 10. Micrograph showing the cross section of a nickel coating produced using PS-TF process in the VLPPS system at Sandia National Laboratories. This coating exhibits the familiar lamellar microstructure of a conventional plasma spray coating, but it is fully dense and less than 100 microns in thickness.

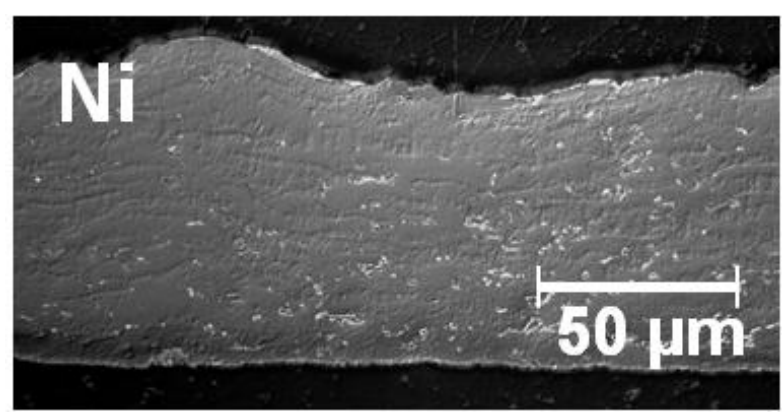

\section{Open Questions-Needed Additional Research}

The work discussed above has clearly demonstrated that VLPPS processes can be used to prepare thin $(1<\mathrm{t}<100 \mu \mathrm{m})$, dense coatings with unique microstructures. Like most thermal spray processes, a wide range of metal, ceramic, and composite feedstocks can be deposited. However, an improved understanding of the VLPPS family of processes would foster more rapid adoption by the thermal spray community. Specific questions yet to be answered include a better understanding of the properties and physics of the plasma jet at greatly reduced chamber pressures, interactions between the plasma and the feedstock, phase transformation pathways for the feedstock, and the mechanism(s) responsible for columnar microstructures.

\section{Summary}

The VLPPS process allows rapid preparation of thin $(1<\mathrm{t}<100$ micron), dense coatings. Microstructures characteristic of both droplet deposition and vapor deposition have been reported by Sulzer-Metco and confirmed by Sandia National Laboratories [3,9]. Deposition rates associated with VLPPS are considerably faster than traditional thin film processes such as PVD and CVD. VLPPS offers the opportunity to bridge the thickness gap between traditional thermal spray and thin film coating processes. In addition, VLPPS offers the ability to create columnar and mixed mode microstructures. Mixed mode deposition is not normally encountered in either thermal spray or PVD/CVD processes. Mixed mode deposition offers the potential to prepare coatings that have properties associated with both vapor deposited microstructures (e.g., strain tolerance due to columnar grain structure) and droplet deposited microstructures (e.g., rapid build rates).

The VLPPS process, by accessing new regions of parameter space, should enable a variety of new coating applications. Current work is focused on thermal barrier coatings and SOFC electrolytes; however, one can envision many other opportunities for VLPPS ceramic, metal, and composite coatings. 
Like most emerging processes, significant gaps currently exist in our understanding of the VLPPS family of processes. These areas include: particle-plasma interactions in the rarefied plasma, particle vaporization and its affect on plasma properties, and deposition mechanisms associated with columnar microstructures. Increased understanding in each of these areas will enable the spray community to more readily apply VLPPS processes to meet emerging coating challenges.

\section{Acknowledgement}

Sandia is a multiprogram laboratory operated by Sandia Corporation, a Lockheed Martin Company, for the United States Department of Energy's National Nuclear Security Administration under contract DE-AC04-94AL85000.

\section{References}

1. Yotsombat, B.; Davydov, S.; Poolcharuansin, P.; Vilaithong, T.; Brown, I. Optical emission spectra of a copper plasma produced by a metal vapour vacuum arc plasma source. J. Phys. D: Appl. Phys. 2001, 34, 1928-1932.

2. Dorier, J.; Gindrat, M.; Hollenstein, Ch.; Loch, M.; Refke, A.; Barbezat, G. Plasma jet properties in a new spraying process at low pressure for large area thin film deposition. In Proceedings of the 2001 International Thermal Spray Conference, Singapore, 28-30 May 2001; pp. 1-6.

3. Refke, A.; Hawely, D.; Doesburg, J.; Schmid, R.K. LPPS thin film technology for the application of TBC systems. In Proceedings of the 2005 International Thermal Spray Conference, May 2005, Basel, Switzerland; pp. 438-443.

4. Refke, A.; Barbezat, G.; Dorier, J.-L.; Gindrat, M.; Hollenstein, Ch. Characterization of LPPS process under various spray conditions for potential applications. In Proceedings of the 2003 International Thermal Spray Conference, 5-8 May 2003, Orlando, FL, USA; pp. 581-588.

5. Dorier, J.L.; Guittienne, Ph.; Hollenstein, Ch.; Gindrat, M.; Refke, A. Mechanisms of films and coatings formation from gaseous and liquid precursors with low pressure plasma spray equipment. Surf. Coat. Technol. 2009, 203, 2125-2130.

6. Von Niessen, K.; Gindrat, M.; Refke, A. Vapor phase deposition using plasma Spray-PVD ${ }^{\mathrm{TM}}$. J. Therm. Spray Technol. 2010, 19, 502-509.

7. Von Niessen, K.; Gindrat, M. Plasma Spray-PVD: A new thermal spray process to deposit out of the vapor phase. J. Therm. Spray Technol. 2011, 20, 736-743.

8. Gindrat, M.; Höhle, H.M.; von Niessen, K.; Guittienne, Ph.; Grange, D.; Hollenstein, Ch. Plasma Spray-CVD: A new thermal spray process to produce thin films from liquid or gaseous precursors. J. Therm. Spray Technol. 2011, 20, 882-887.

9. Spinhirne, N.R. The Development and Characterization of Novel Yttria-Stabilized Zirconia Coatings Deposited by Very Low Pressure Plasma Spray; MS Thesis; New Mexico Institute of Mining and Technology: Socorro, NM, USA, December 2008. 
10. Yanar, N.M.; Helminiak, M.; Meier, G.H.; Pettit, F.S. Comparison of the failures during cyclic oxidation of yttria-stabilized ( 7 to 8 weight percent) zirconia thermal barrier coatings fabricated via electron beam physical vapor deposition and air plasma spray. Metall. Mater. Trans. A 2011, 42A, 905-921.

11. Hospachm A.; Mauer, G.; Vaßen, R.; Stöver, D. Columnar-Structured Thermal Barrier Coatings (TBCs) by Thin Film Low-Pressure Plasma Spraying (LPPS-TF). J. Therm. Spray Technol. 2011, 20, 116-120.

12. Zhang, N.; Sun, F.; Zhu, L.; Verdy, C.; Planche, M.P.; Dong, C.; Coddet, C. Characteristics of Cu film deposited using VLPPS. J. Therm. Spray Technol. 2011, 20, 351-357.

13. Mauer, G.; Vaßen, R.; Stöver, D. Thin and dense ceramic coatings by plasma spraying at very low pressure. In Proceedings of the International Thermal Spray Conference, Las Vegas, NV, USA, 2009; pp. 773-778.

14. Zhu, L.; Zhang, N.; Bolot, R.; Planche, M.P.; Liao, H.; Coddet, C. Thin yttria-stabilized zirconia coatings deposited by low-energy plasma spraying under very low pressure condition. J. Therm. Spray Technol. 2011, 20, 1-7.

15. Hall, A.C.; McCloskey, J.F.; Urrea, D.A.; Roemer, T.J.; Beatty, D.E.; Spinhirne, N.R.; Hirschfeld, D.A. Low pressure plasma spray-Thin Film ${ }^{\circledR}$ at sandia national laboratories. In Proceedings of the International Thermal Spray Conference, Las Vegas, NV, USA, May 2009; pp. 725-728.

16. Fauchais, P.; Vardelle, A. Innovative and emerging processes in plasma spraying: from micro- to nano-structured coatings. J. Phys. D: Appl. Phys. 2011, 44, 1-14.

17. Von Niessen, K.; Gindrat, M. Vapor phase deposition using a plasma spray process. In Thermal Spray: Global Solutions; In Proceedings of the International Thermal Spray Conference, Düsseldorf, Germany, May 2010; pp. 219-227.

18. Sokolov, D. E.; Chwa, S.O.; Klein, D.; Coddet, C.; Nardin, P. Coatings obtained by low pressure plasma spraying. In Proceedings of the International Thermal Spray Conference, Basel, Switzerland, May 2005; pp. 450-453.

19. Fleetwood, J.; Trice, R.; Slamovich, E.; Hall, A.; McCloskey, J. Solid oxide fuel cell electrolytes produced by a combination of suspension plasma spray and very low pressure plasma spray. In Proceedings of the Materials Science \& Technology Conference, Houston, TX, USA, October 2010; CD only volume.

20. Lang, M.; Henne, R.; Schaper, S.; Schiller, G. Development and characterization of vacuum plasma sprayed thin film solid oxide fuel cells. J. Therm. Spray Technol. 2001, 10, 618-625.

21. Jia, L.; Gitzhofer, F. Induction plasma synthesis of nano-structured SOFCs electrolyte using solution and suspension plasma spraying: A comparative study. J. Therm. Spray Technol. 2010, 19, 566-574.

22. Lang, M.; Franco, T.; Schiller, G.; Wagner, N. Electrochemical characterization of vacuum plasma sprayed thin-film solid oxide fuel cells (SOFC) for reduced operating temperatures. J. Appl. Electrochem. 2002, 32, 871-874. 
23. Hui, R.; Wang, Z.; Kesler, O.; Rose, L.; Jankovic, J.; Yick, S.; Maric, R.; Ghosh, D. Thermal plasma spraying for SOFCs: Applications, potential advantages, and challenges. J. Power Sources 2007, 170, 308-323.

24. Franco, T. Z. HoshiarDin, T.; Szabo, P.; Lang, M.; Schiller, G. Plasma sprayed diffusion barrier layers based on doped perovskite-type $\mathrm{LaCrO}_{3}$ at substrate-anode interface in solid oxide fuel cells. J. Fuel Cell Sci. Tech. 2007, 4, 406-412.

25. Henne, R. Solid oxide fuel cells: A challenge for plasma deposition processes. J. Therm. Spray Technol. 2007, 16, 381-403.

26. Fauchais, P.; Montavon, G.; Bertrand, G. From powders to thermally sprayed coatings. J. Therm. Spray Technol. 2010, 19, 56-80.

27. Guittienne, Ph.; Hollensteinm, Ch.; Dorier, J.L.; Gindrat, M.; Refke, A. Use of low-pressure plasma spraying equipment to produce thin films and thick coatings using liquid and gaseous precursors. In Thermal Spray 2009; In Proceedings of the International Thermal Spray Conference, Las Vegas, NV, USA, May 2009; pp. 741-745.

28. Rousseau, F.; Awamat, S.; Morvan, D.; Amourox, J.; Mevrel, R. Deposition of thick oxide layers from solutions in a low pressure plasma reactor. Surf. Coat. Technol. 2007, 202, 714-718.

29. Jodoin, B.; Gindrat, M.; Dorier, J.L.; Hollenstein, C.; Lcoh, M.; Barbezat, G. Modeling and diagnostics of a supersonic DC plasma jet expanding at low pressure. In Proceedings of the International Thermal Spray Conference, Essen, Germany, March 2002; pp. 716-720.

30. Gindrat, M.; Dorier, J.-L; Hollenstein, Ch.; Loch, M.; Refke, A.; Salito, A.; Barbezat, G. Effect of specific operation conditions on the properties of LPPS plasma jets expanding at low pressure. In Proceedings of the International Thermal Spray Conference, Essen, Germany, March 2002; pp. 459-464.

31. Bolot, R.; Klein, D.; Coddet, C. Design of a nozzle extension for thermal spray under very low pressure conditions. In Proceedings of the International Thermal Spray Conference, Osaka, Japan, May 2004; pp. 574-579.

32. Kingswell, R.; Scott, K.T.; Wassel, L.L. Optimizing the vacuum plasma spray deposition of metal, ceramic, and cermet coatings using designed experiments. J. Therm. Spray Technol. 1993, 2, 179-185.

33. Bolot, R.; Sokolov, D.; Klein, D.; Coddet, C. Nozzle developments for thermal spray at very low pressure. J. Therm. Spray Technol. 2006, 15, 827-833.

34. Mauer, G.; Vaßen, R.; Stöver, D. Plasma and particle temperature measurements in thermal spray: Approaches and applications. J. Therm. Spray Technol. 2011, 20, 391-406.

35. Yoshida, T. Toward a new era of plasma spray processing. Pure Appl. Chem. 2006, 78, 1093-1107.

36. Dhiman, R.; Chandra, S. Predicting splat morphology in a thermal spray process. Surf. Coat. Technol. 2007, 201, 789-801. 
37. Fauchais, P.; Fukumoto, M.; Vardelle, A.; Vardelle, M. Knowledge concerning splat formation: An invited review. J. Therm. Spray Technol. 2004, 13, 337-360.

(C) 2011 by the authors; licensee MDPI, Basel, Switzerland. This article is an open access article distributed under the terms and conditions of the Creative Commons Attribution license (http://creativecommons.org/licenses/by/3.0/). 